\title{
PRODUÇÃO DE ACETATO DE n-BUTILA VIA DESTILAÇÃO REATIVA
}

\section{PRODUCTION OF n-BUTYL ACETATE VIA REACTIVE DISTILLATION}

\section{Jr. BRAVIM ${ }^{1, *}$ e A. P. AFONSO ${ }^{1}$}

${ }^{1}$ Universidade Estadual de Campinas, Faculdade de Engenharia Química, Departamento de Engenharia de Processos, Campinas, São Paulo, Brasil

${ }^{*}$ Autor correspondente: Universidade Estadual de Campinas, Faculdade de Engenharia Química, Departamento de Engenharia de Processos, Campinas, São

Paulo, Brasil, Fone: +55 1935213910

Endereço de e-mail: v.bravim.j@gmail.com (V. Jr. Bravim).

\begin{tabular}{l} 
A R T I C L E I N F O \\
\hline Article history: \\
Received 2018-10-20 \\
Accepted 2018-11-20 \\
Available online 2019-03-08 \\
pa lavra - ch $a v e$ \\
Destilação reativa \\
Acetato de butila \\
Esterificação \\
Simulação \\
$k$ e y wo r $d s$ \\
Reactive distillation \\
Butyl acetate \\
Esterification \\
Simulation
\end{tabular}

R E S U M O

A produção de acetato de n-butila por meio da esterificação do ácido acético com o n-butan1-ol via destilação reativa foi avaliada por simulação computacional. Este processo já foi amplamente estudado, entretanto este trabalho apresenta uma nova discussão sobre a influência dos parâmetros operacionais da coluna na conversão de n-butan-1-ol e pureza de acetato de $n$-butila. Todas as simulações foram realizadas no programa Aspen Plus empregando o método de propriedade UNIQUAC e um modelo cinético pseudohomogêneo para a esterificação com o módulo RadFrac. Um processo otimizado foi obtido para uma alimentação de $50 \mathrm{kmol} / \mathrm{h}$, em uma coluna de 15 estágios, com uma conversão de n-butan-1ol de 99,22 \% e pureza de acetato de n-butila de 99,60\%.

A B S T R A C T
The production of n-butyl acetate by esterification of acetic acid with n-butan-1-ol via reactive
distillation was evaluated by computational simulations. This process has already been vastly
studied, however, this work presents a new discussion about the influence of column operating
parameters on the $n$-butan-1-ol conversion and n-butyl acetate purity. All simulations were
performed in Aspen Plus software employing UNIQUAC property method and a pseudo-
homogeneous kinetic model for the esterification with the RadFrac module. An optimized
process was encountered for a feed of 50 kmol/h into a column of 15 stages, maintaining a n-
butan-1-ol conversion of $99.22 \%$ and n-butyl acetate purity of $99.60 \%$.




\section{N O M E N C L A T U RA}

\begin{tabular}{ll} 
BuOAc & acetato de n-butila \\
BuOH & n-butan-1-ol \\
CTA & custo total anual \\
DR & destilação reativa \\
HOAc & ácido acético \\
$\mathrm{HOH}$ & água \\
$v_{i}$ & coeficiente estequiométrico do componete $i$ \\
$A$ & corrente aquosa \\
$a_{i}$ & coeficiente de atividade do componente $i$ \\
$B$ & corrente de fundo \\
$D a$ & número de Damkohler \\
$E_{\mathrm{A}, \mathrm{i}}$ & energia de ativação \\
$F$ & corrente de alimentação \\
$\mathrm{K}_{\mathrm{i}}$ & constante da taxa da reação \\
$\mathrm{K}_{i}{ }_{i}$ & fator de frequência \\
$\mathrm{M}_{\text {cat }}$ & massa de catalisador \\
$\mathrm{N}_{\mathrm{i}}$ & número de mols da espécie $i$ \\
$R$ & constante dos gases ideais \\
$T$ & temperatura \\
$t$ & tempo \\
\hline
\end{tabular}

\section{INTRODUÇÃO}

$\mathrm{O}$ acetato de n-butila (BuOAc) é um composto com extensa aplicação na indústria. Ele é utilizado na formulação de solventes para adequar a viscosidade e melhorar as propriedades fluidas das tintas. Além disso, o BuOAc é um componente na formulação de produtos como copolímeros de cloreto de vinila, poliestireno e resinas sintéticas (Stoye, 2000). Ele é sintetizado por meio da reação de esterificação do ácido acético (HOAc) com o n-butan-1-ol (BuOH), na presença de catalisador ácido. A água (HOH) é o outro produto da reação (Tian et al., 2012). A reação é levemente exotérmica e tem entalpia de $-18,7 \mathrm{~kJ} / \mathrm{mol}$ (Sert e Atalay, 2011; Tian et al., 2012). Reações de esterificação são controladas por equilíbrio químico. $O$ equilíbrio pode ser deslocado para o sentido direto da reação por meio da remoção contínua dos produtos (Cho et al., 2014).

Assim é possível realizar a esterificação e a remoção contínua dos produtos por meio da destilação reativa (DR). A DR compatibiliza a reação química e a destilação em um único aparato industrial. Sua aplicação ganhou notoriedade na década de 1980 devido à elevada demanda de metil tertc-butil éter. Segundo Hiwale et al. (2004) e Malone e Doherty (2000), a DR apresenta vantagens como conversão elevada dos reagentes, superação de azeótropos, redução do número de equipamentos e maior seletividade.

De acordo com a literatura, a produção de BuOAc por meio da DR foi amplamente estudada. Diferentes configurações foram propostas para esse processo. Os reagentes podem ser introduzidos diretamente na coluna de DR ou em um pré-reator e, posteriormente encaminhados para a coluna de DR em equilíbrio químico com os produtos. Além disso, pode-se optar pela introdução dos reagentes e de um componete de arraste externo diretamente na coluna de DR (Cho et al., 2014).

Hanika et al. (1999) propuseram o estudo da produção de BuOAc via DR, experimentalmente e por simulação computacional. O processo foi estudado com base nas configurações com e sem pré-reator. As simulações foram realizadas no programa Aspen Plus, com base nas hipóteses de equlíbrio químico e equilíbrio líquido-vapor em todos os estágios, além da queda de pressão desprezível ao longo da coluna. Investigou-se a dependência da conversão de HOAc e da pureza de BuOAc com relação à vazão mássica. Maior conversão foi alcançada em vazões mássicas mais baixas. A pureza de BuOAc foi investigada em relação à razão entre as vazões da corrente de destilado e de alimentação, somente para a configuração com o pré-reator. Desse modo, para valores de aproximadamente 4,5, maior pureza foi obtida. Boa concordância entre os dados experimentais e simulados foi alcançada.

Steinigeweg e Gmehling (2002) investigaram as propriedades termodinâmicas do sistema HOAc-BuOHBuOAc-HOH e obtiveram um modelo cinético para ele. O método de propriedade UNIQUAC foi empregado para o cálculo dos coeficientes de atividade. O modelo cinético obtido foi utilizado para a realização de simulações no programa Aspen Plus, com base no módulo RadFrac. A conversão de $\mathrm{BuOH}$ foi escolhida como critério para a avaliação do desempenho da DR. Assim, os parâmetros operacionais variados foram: carga térmica do refervedor, vazão e posição da corrente de alimentação na seção reativa e o número de estágios reativos. Para as configurações com e sem pré-reator, a alimentação dos reagentes no topo da seção reativa produziu elevadas conversões no consumo de altas cargas térmicas do refervedor. Com o préreator menos estágios reativos foram necessários para alcançar altas conversões. Em ambas configurações foi observado que vazões de alimentação mais baixas requereram menos estágios reativos para obter conversões mais altas.

Singh et al. (2005) estudaram por experimentos e simulações computacionais a produção de BuOAc via DR. A configuração que utiliza um pré-reator foi considerada. A cinética apresentada por Gangadwala et al. (2003) — LHHW modificado - foi utilizada para as simulações. A conversão de $\mathrm{BuOH}$ e a pureza de BuOAc foram escolhidas como critério de avaliação do desempenho da DR. Os seguintes parâmetros operacionais foram variados: vazão e posição da corrente de alimentação na seção reativa, razão molar entre o $\mathrm{BuOH}$ e o HOAc e número de Damkohler (Da). Menores vazões da corrente de alimentação produziram conversões e purezas elevadas. A alimentação feita no topo da seção reativa produziu maior conversão e pureza. Razões molar próximas à unidade resultaram nos maiores valores de conversão e de pureza. Baixa pureza foi encontrada quando a coluna operou em baixos $\mathrm{Da}$ (entre 1 e 10 aproximadamente), além disso, verificou-se que o desempenho da DR foi controlado pela cinética da reação. Em altos Da (entre $10^{3}$ e $10^{4}$ aproximadamente) alta pureza foi obtida, e o desempenho da DR foi controlado pelos fenômenos de transporte.

Tian et al. (2012) estudaram a produção de BuOAc por DR. Os autores utilizaram o programa Aspen Plus e o módulo 
RadFrac para descrever o processo. O método de propriedade UNIQUAC foi utilizado para descrever o equilíbrio de fases do sistema. A cinética desenvolvida por Qiu et al. (2009) foi incorporada à simulação por meio de subrotina Fortran. A simulação foi validada por meio de experimentos. Todo o processo considerou o uso de pré-reator. O desempenho do processo foi avaliado com base na conversão de $\mathrm{BuOH}$ e pureza de BuOAc. Os parâmetros número de estágios reativos, número de estágios não reativos, posição da corrente de alimentação na seção reativa e carga térmica do refervedor foram estudados. $\mathrm{O}$ aumento do número de estágios reativos levou à maior conversão, pureza e carga térmica do refervedor. O mesmo resultado foi observado para o número de estágios não reativos, em que foram variados separadamente o número de estágios de retificação e de esgotamento. A corrente de alimentação deve ser introduzida acima do primeiro estágio reativo, de modo que nessa posição elevada conversão e pureza foram alcançadas, além de que, o consumo de carga térmica do refervedor foi razoável. Os autores concluíram o estudo com um projeto otimizado capaz de atingir conversão e pureza maior do que $96 \%$. Além disso, eles classificaram a simulação como capaz de fornecer resultados adequados.

Cho et al. (2014) avaliaram computacionalmente o desempenho da produção de BuOAc via DR considerando a alimentação de cicloexano como componente de arraste externo. O modelo cinético proposto por Steinigeweg e Gmehling (2002) foi utilizado. O método UNIQUAC e o módulo RadFrac do programa Aspen Plus foram adotados para as simulações. Os seguintes parâmetros operacionais foram variados: carga térmica do refervedor, posição da corrente de alimentação na seção reativa e o número de estágios reativos. Além disso, o custo total anual (CTA) foi avaliado. Como critério de avaliação do desempenho da DR escolheu-se o rendimento de BuOAc. O aumento da carga térmica do refervedor produziu maior rendimento. $\mathrm{O}$ emprego do cicloexano permitiu que rendimentos similares ao processo com pré-reator fossem alcançados, porém exigindo menores cargas térmicas. Foi encontrada diferença no rendimento quando as simulações avaliaram cargas térmicas variando-as crescentemente e descrescentemente. Essa diferença foi associada ao fenômeno de múltiplos estados estacionário. Quando a alimentação foi feita na metade da seção reativa foi obtido rendimento elevado. Para uma alimentação de $72 \mathrm{kmol} / \mathrm{h}$, em torno de 10 estágios reativos foram necessários para obter o maior rendimento. Concluiu-se que o uso do componente de arraste resulta em um processo com rendimento elevado e o menor CTA quando comparado às configurações com pré-reator e sem pré-reator.

Embora muito tenha sido explorado sobre a produção de BuOAc via DR, este trabalho objetivou ampliar e detalhar a investigação do efeito da variação dos parâmetros operacionais da coluna no desempenho do processo. Alguns parâmetros como a posição da seção reativa na coluna e a temperatura de saída do fluido de processo no condensador ainda não foram investigados. Além disso, a maioria dos estudos foram realizados considerando a presença de um pré-reator conforme os resultados de Steinigeweg e Gmehling (2002). No presente trabalho foi considerada somente a configuração sem pré-reator, ou seja, alimentação dos reagentes diretamente na coluna. As análises foram realizadas somente por simulação computacional.

\section{MATERIAIS E MÉTODOS}

O programa Aspen Plus 8.8 foi utilizado para a realização das simulações. O processo foi simulado em estado estacionário de acordo com o módulo RadFrac. Os componentes $\mathrm{HOAc}, \mathrm{BuOH}, \mathrm{BuOAc}$ e $\mathrm{HOH}$ foram incluídos e o método baseado em coeficiente de atividade UNIQUAC foi selecionado para modelar o equilíbrio de fases do sistema. Os parâmetros de interação binária foram preenchidos pelo banco de dados do programa Aspen Plus. Os azeótropos presentes no sistema foram calculados e comparados com os dados da literatura, conforme apresentado nas Tabelas 1 e 2. Observa-se excelente concordância em relação às temperaturas e a maioria dos azeótropos.

\begin{tabular}{|cc|ccc|}
\multicolumn{5}{c}{ Tabela 1 - Azeótropos calculados para esse trabalho. } \\
\hline HOAc & $\mathrm{BuOH}$ & $\mathrm{BuOAc}$ & $\mathrm{HOH}$ & Temperatura $/{ }^{\circ} \mathrm{C}$ \\
- & - & 0,2928 & 0,7072 & 90,60 \\
- & 0,1010 & 0,2098 & 0,6892 & 90,08 \\
- & 0,7802 & 0,2198 & - & 116,98 \\
0,3150 & 0,1608 & 0,5242 & - & 122,85 \\
- & 0,2483 & - & 0,7517 & 92,61 \\
0,5087 & 0,4913 & - & - & 127,63
\end{tabular}

Tabela 2 - Azeótropos obtidos na literatura.

$\begin{array}{cccccc}\text { HOAc } & \mathrm{BuOH} & \mathrm{BuOAc} & \mathrm{HOH} & \begin{array}{c}\text { Temperatura } \\ /{ }^{\circ} \mathrm{C}\end{array} & \text { Fonte } \\ - & - & 0,2766 & 0,7234 & 91,19 & \\ - & 0,0895 & 0,2041 & 0,7064 & 90,66 & a \\ - & 0,7004 & 0,2996 & - & 116,15 & \\ 0,4600 & 0,2000 & 0,3400 & - & 121,30 & b \\ - & 0,2334 & - & 0,7666 & 92,96 & a \\ 0,4839 & 0,5161 & - & - & 122,69 & a\end{array}$

Nota: $a$ e $b$ designam os trabalhos feitos por Loning et al. (2000) e Cardona et al. (2004), respectivamente.

\subsection{Fluxograma do Processo}

Foi desenvolvido um fluxograma para o processo de produção de BuOAc, conforme apresentado na Figura 1. O processo se iniciou a partir de uma corrente de alimentação, que introduziu uma mistura de $\mathrm{HOAc}$ e $\mathrm{BuOH}$ à coluna de DR. Os reagentes foram alimentados e misturados em uma única corrente devido à similaridade em seus pontos de ebulição $\left(117,90{ }^{\circ} \mathrm{C}\right.$ HOAc, $117,70{ }^{\circ} \mathrm{C} \mathrm{BuOH}, 126,00{ }^{\circ} \mathrm{C}$ BuOAc e $\left.100,00{ }^{\circ} \mathrm{C} \mathrm{HOH}\right)$. Na seção reativa, $\mathrm{HOAc}$ e $\mathrm{BuOH}$ reagiram formando BuOAc e $\mathrm{HOH}$. A corrente de produto de topo foi encaminhada para um condensador. A saída do condensador estava conectada a um decantador. No decantador, a corrente de produto de topo condensada foi separada em duas fases. Uma foi a fase orgânica e a outra foi a fase aquosa. A fase orgânica seguiu como corrente de refluxo orgânico e foi introduzida na coluna, de modo a reaproveitar os reagentes e aumentar a produção de BuOAc. A fase aquosa foi concluída no processo. A corrente de produto de fundo também foi concluída no processo.

A coluna operou sob pressão atmosférica e possuiu 21 estágios, sendo o último o refervedor. Os estágios foram enumerados em ordem crescente, do topo para o fundo. A seção reativa foi do $6^{\circ}$ ao $15^{\circ}$ estágio. A vazão da corrente de alimentação foi de $50 \mathrm{kmol} / \mathrm{h}$, com uma razão molar entre o $\mathrm{BuOH}$ e o HOAc de 1. A alimentação foi realizada no topo da seção reativa, ou seja, acima do $6^{\circ}$ estágio, em uma temperatura de $110^{\circ} \mathrm{C}$ e pressão de $1 \mathrm{~atm}$. A corrente de refluxo orgânico foi 
alimentada no topo da coluna, ou seja, acima do $1^{\circ}$ estágio. Foi configurado que $15 \%$ da corrente de alimentação saísse como produto de fundo. Isso exigiu do refervedor uma carga térmica de $1751 \mathrm{~kW}$. A temperatura de saída da corrente de produto de topo no condensador foi de $50{ }^{\circ} \mathrm{C}$, o que resultou na absorção de uma carga térmica de $1977,75 \mathrm{~kW}$. Sua pressão de operação foi de $1 \mathrm{~atm}$. Cada estágio reativo foi projetado para comportar 106 $\mathrm{kg}$ de carga de líquido. O decantador foi configurado para operar em modo adiabático. Assumiu-se a queda de pressão como desprezível ao longo da coluna. As reações aconteceram somente na fase líquida. A formação de duas fases líquidas foi considerada somente dentro do decantador.

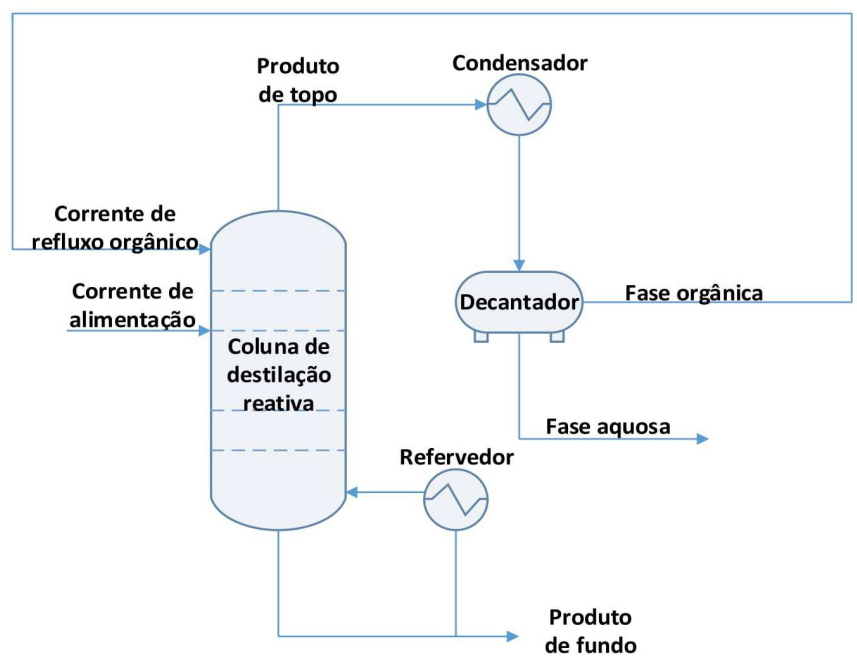

Figura 1 - Fluxograma do processo de produção de BuOAc.

O desempenho da coluna foi estudado com base na conversão de $\mathrm{BuOH}$, definida conforme a Equação 1 e pureza de BuOAc na corrente de produto de fundo. A distribuição de fração molar e de temperatura ao longo da coluna foram estudadas. O efeito da variação dos seguintes parâmetros operacionais foram estudados: vazão da corrente de alimentação, razão molar dos reagentes na corrente de alimentação, número de estágios reativos, número de estágios não reativos, localização da corrente de alimentação na seção reativa, localização da seção reativa na coluna, carga térmica do refervedor e temperatura de saída da corrente de produto de topo no condensador.

$$
X_{B u O H}=\frac{F-B-A}{F}
$$

\subsection{Cinética de Reação}

O modelo cinético desenvolvido por Steinigeweg e Gmehling (2002) foi adotado para descrever a Equação 2. O modelo é do tipo pseudohomogêneo e baseado em coeficientes de atividade, conforme apresentado na Equação 3. A dependência da temperatura foi descrita por meio da Lei de Arrhenius, de acordo com a Equação 4. Os parâmetros cinéticos desse modelo estão apresentados na Tabela 3.

$$
\mathrm{HOAc}+\mathrm{BuOH} \rightleftarrows \mathrm{BuOAc}+\mathrm{HOH}
$$

$$
\begin{aligned}
& r_{\text {BuOAc }}=\frac{1}{m_{c a t}} \frac{1}{v_{i}} \frac{d n_{i}}{d t}=k_{1} a_{\mathrm{HOAc}} a_{\mathrm{BuOH}}-k_{-1} a_{\mathrm{BuOAc}} a_{\mathrm{HOH}} \\
& k_{i}=k_{i}^{0} \exp \left(\frac{-E_{A, i}}{R T}\right)
\end{aligned}
$$

Tabela 3 - Valores dos parâmetros cinéticos para o modelo pseudohomogêneo proposto por Steingewg e Gmehling

(2002).

\begin{tabular}{cccc} 
Reação & $i$ & $k_{i}^{0} / \mathrm{mol} \mathrm{g}^{-1} \mathrm{~s}^{-1}$ & $E_{A, i} / \mathrm{kJ} \mathrm{mol}^{-1}$ \\
\hline Esterificação & 1 & 61084 & 56,67 \\
Hidrólise & -1 & 98420 & 67,66
\end{tabular}

\section{RESULTADOS E DISCUSSÃO}

\subsection{Resultados Globais do Processo}

A Figura 2 apresenta a fração molar global dos componentes obtida na simulação. Desejava-se que a corrente de produto de topo fosse principalmente constituída de $\mathrm{HOH}$. Entretanto, o $\mathrm{BuOH}$ e o $\mathrm{BuOAc}$ estiveram presentes em proporções próximas à da $\mathrm{HOH}$. A maior parte do $\mathrm{HOAc}$ introduzida na coluna foi consumida.

As frações obtidas para o $\mathrm{BuOH}$ e o BuOAc ocorreram devido à formação de azeótropo. Conforme apresentado na Tabela 1, em aproximadamente $92{ }^{\circ} \mathrm{C}, 91{ }^{\circ} \mathrm{C}$ e $90{ }^{\circ} \mathrm{C}$, a $\mathrm{HOH}$ formou azeótropo com o $\mathrm{BuOH}$, com o $\mathrm{BuOAc}$ e com ambos, respectivamente. Eles prejudicaram o desempenho da DR, pois esperava-se que o $\mathrm{BuOH}$ fosse distribuído e consumido na seção reativa, e que todo o BuOAc estivesse livre para ser purificado ao longo da seção de esgotamento.

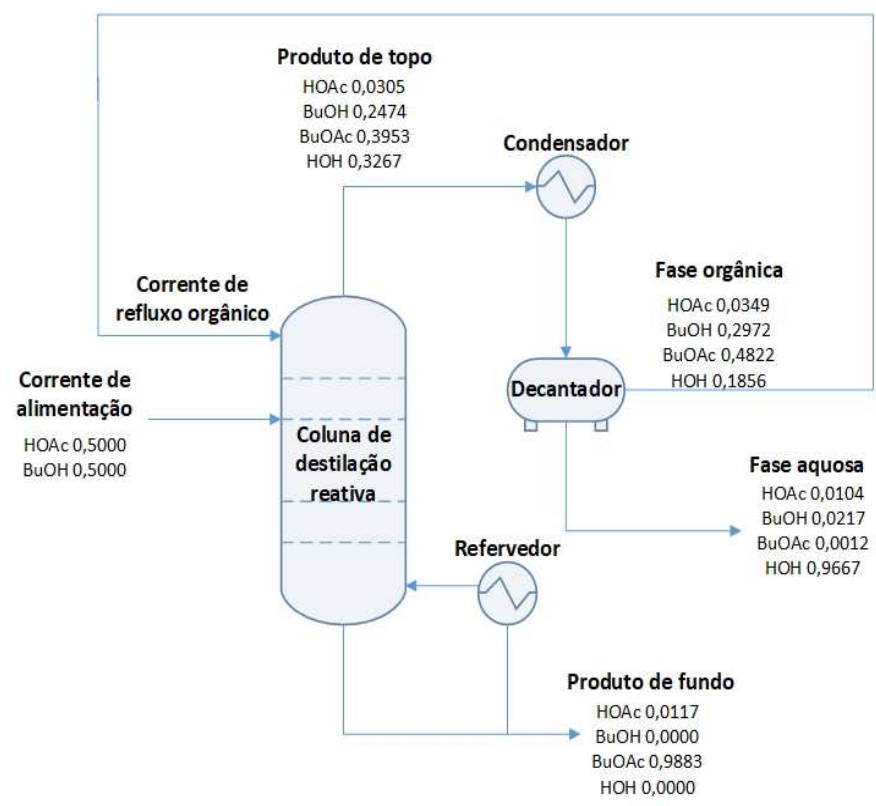

Figura 2 - Fração molar global obtida para as principais correntes do processo.

A fase orgânica obtida na operação de separação comparada à corrente de produto de topo, apresentou moderado aumento na fração molar de $\mathrm{BuOH}$ e de $\mathrm{BuOAc}$. Houve redução 
significativa na fração molar de $\mathrm{HOH}$. Houve variação muito pequena na fração molar de HOAc. O refluxo da fase orgânica contribuiu com o reaproveitamento dos reagentes. Contrariamente, a presença de $\mathrm{BuOAc}$ e de $\mathrm{HOH}$ nessa corrente, contribuiu para a reação reversa.

A fase aquosa apresentou elevada fração molar de $\mathrm{HOH}$. Além disso, nessa fase foram obtidas pequenas quantidade dos reagentes e uma quantidade mínima de BuOAc. A corrente de produto de fundo foi majoritariamente constituída por BuOAc. Esse resultado indica que a coluna projetada foi capaz de esgotar os demais componentes e produzir BuOAc com pureza elevada.

\subsection{Distribuição de Fração Molar}

O desempenho das seções de separação e de reação química estão apresentados nas Figuras 3 (a) e 3 (b). A seção de retificação não enriqueceu satisfatoriamente a $\mathrm{HOH}$. Acreditase que isso aconteceu por causa da formação do azeótropo ternário $\mathrm{BuOH}-\mathrm{BuOAc}-\mathrm{HOH}$, e dos azeótropos binários $\mathrm{BuOH}$ $\mathrm{HOH}$ e BuOAc-HOH (Tabela 1), além do despejo do demais componentes, realizado pela alimentação da corrente de refluxo orgânico, conforme apresentado na constituição da fase orgânica na Figura 2. Somente uma tendência no enriquecimento da $\mathrm{HOH}$ foi observada para a fase vapor, conforme apresentado na Figura 3 (b).

De acordo com as Figuras 3 (a) e 3 (b), a seção reativa apresentou bom desempenho. Os reagentes foram consumidos e a $\mathrm{HOH}$ foi esgotada, levando à alta fração molar de BuOAc. Isso indica que a quantidade de estágios projetados foram suficientes para realizar a separação, e que a carga de líquido empregada por estágio reativo produziu a reação direta em intensidade satisfatória.

Em continuidade, na seção de esgotamento a maior parte do HOAc restante foi separado, conferindo alta pureza de BuOAc na corrente de fundo. O HOAc esteve em quantidades significativas na maioria dos estágios inferiores ao de sua alimentação fresca. Foi necessário seu consumo na seção reativa e sua passagem até os últimos estágios para que ele fosse satisfatoriamente esgotado.

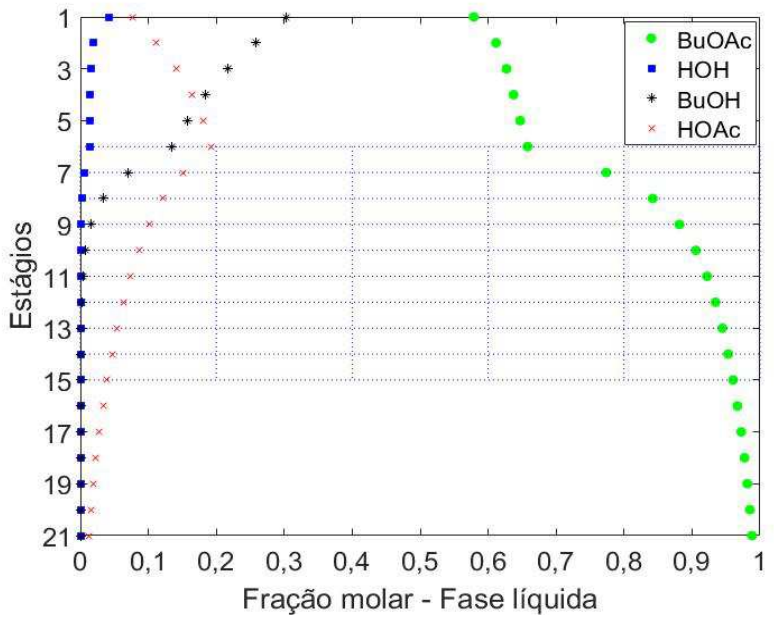

(a)

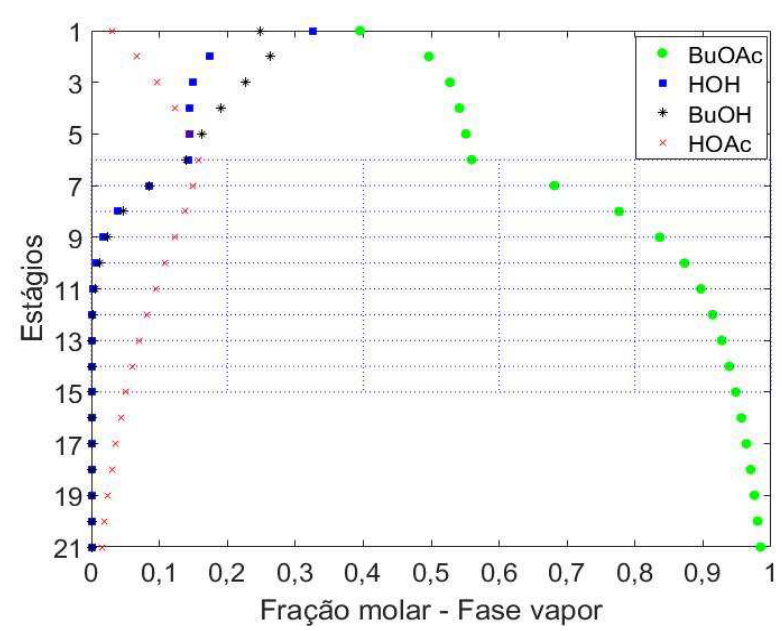

(b)

Figura 3 - Distribuição da fração molar dos componentes ao longo da coluna: (a) fase líquida; (b) fase vapor. A região hachurada indica a seção reativa.

Isso indica que o HOAc apresenta uma tendência em constituir a corrente de produto de fundo. Diferentemente do $\mathrm{BuOH}$ e da $\mathrm{HOH}$ que foram esgotados até um valor de fração molar próximo zero, ele permaneceu em concentrações significativas nas seções reativa e de esgotamento. Nesse sentido, acredita-se que a localização de sua alimentação, o número e a função dos estágios que ele passará, podem influenciar fortemente o desempenho da DR.

\subsection{Distribuição de Temperatura}

A Figura 4 apresenta a distribuição de temperatura ao longo da coluna. Na seção de retificação o perfil formado tendeu a alcançar um máximo em aproximadamente $119{ }^{\circ} \mathrm{C}$. Essa tendência foi interrompida pelo início da seção reativa. Nela a temperatura foi elevada devido à natureza exotérmica da reação e também à maior carga térmica absorvida pelo vapor originado no refervedor, dada a menor distância até ele.

O perfil começou a se estabilizar no nono estágio, indicando que desse estágio em diante a reação ocorreu em uma taxa menor, e portanto liberou calor em menor intensidade. A faixa de temperatura da seção reativa foi de $118,51{ }^{\circ} \mathrm{C}$ até $125,58^{\circ} \mathrm{C}$. Alguns autores relataram o uso de catalisadores com estabilidade térmica estava na faixa de $125{ }^{\circ} \mathrm{C}$ até $130{ }^{\circ} \mathrm{C}$ (Gangadwala et al., 2003; Singh et al., 2005). 


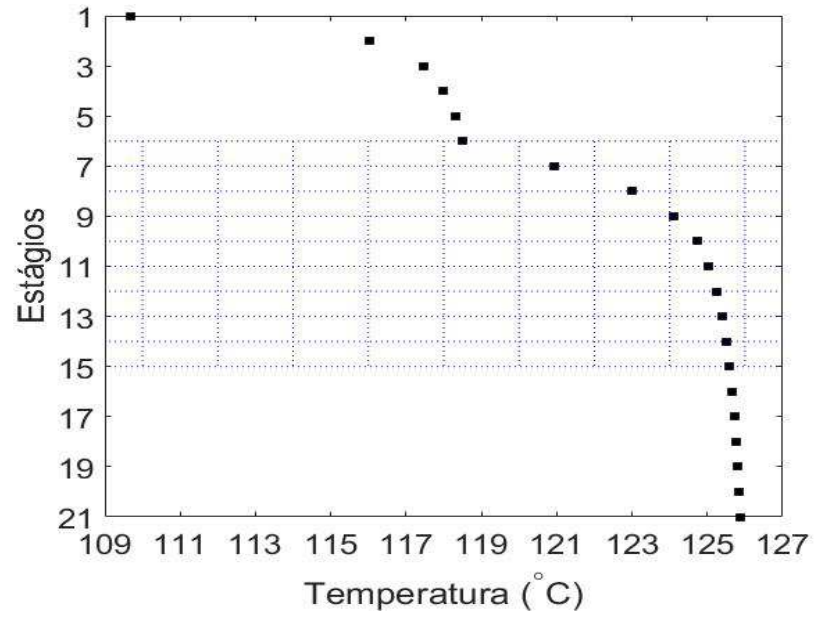

Figura 4 - Distribuição de temperatura ao longo da coluna.

É importante projetar a coluna de modo que a seção reativa não alcance temperaturas prejudiciais à atividade do catalisador, afetando seu tempo de vida útil, a taxa da reação química e a necessidade de desativação da planta industrial para a manutenção do catalisador (Sakuth et al., 2008). A temperatura se manteve ao longo da seção de esgotamento. $\mathrm{O}$ maior valor de temperatura alcançado na coluna foi de aproximadamente $125,86^{\circ} \mathrm{C}$.

\subsection{Influência da Vazão da Corrente de Alimentação}

Os resultados da Figura 5 apresentam a influência da vazão da corrente de alimentação na conversão de $\mathrm{BuOH}$ e na pureza de BuOAc. Em baixas vazões foram alcançadas elevada conversão e pureza. A medida que a vazão aumentou ambos parâmetros foram reduzidos. Em altas vazões o tempo de residência dos reagentes não foi suficiente para que a reação ocorresse em uma taxa satisfatória, de modo a consumir o $\mathrm{BuOH}$ e produzir o BuOAc (Singh et al., 2005).

Embora operar em baixas vazões resulte nos melhores valores de conversão e de pureza, há a desvantagem de que essas configurações levem à menor produtividade. Quando comparado os extremos de vazão, operar no maior valor resulta na queda de aproximadamente $1,2 \%$ na pureza de BuOAc. Contudo, nessa configuração a corrente de produto de fundo possui uma vazão aproximadamente 10 vezes maior.

Quanto maior a vazão, mais BuOAc é produzido. Assim, é necessário a orientação de métodos que avaliem custos e/ou lucros para decidir qual dessas configurações otimiza o projeto. Em síntese, a ponderação deve ser feita com base nos seguintes itens: (i) Produzir pouco BuOAc, porém em elevada pureza; (ii) produzir muito BuOAc, porém em baixa pureza; (iii) produzir BuOAc em quantidade e pureza razoáveis.

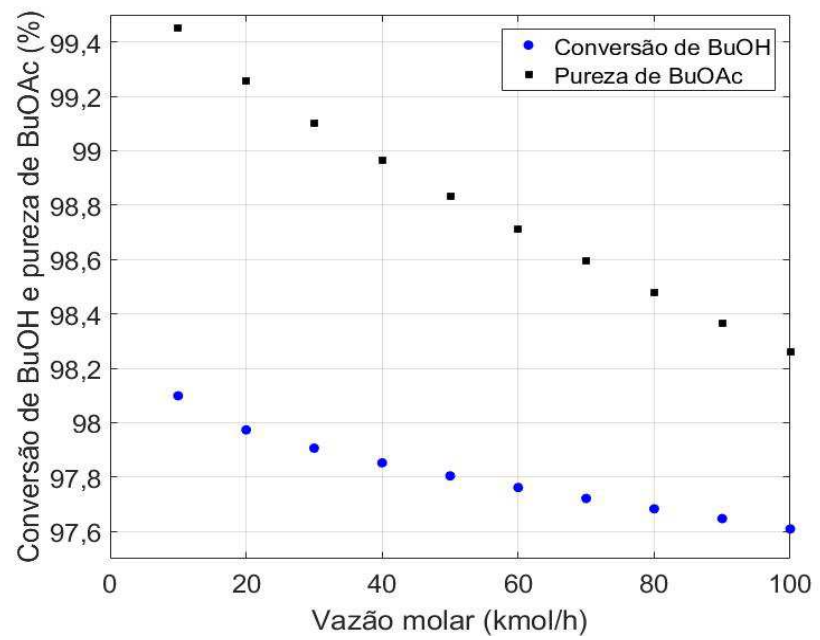

Figura 5 - Influência da vazão no desempenho da DR.

\subsection{Influência da Razão Molar dos Reagentes na Alimentação}

A Figura 6 apresenta os resultados da conversão de $\mathrm{BuOH}$ e da pureza de $\mathrm{BuOAc}$ quando a razão molar entre $\mathrm{BuOH}$ e HOAc na corrente de alimentação foi variada. Quando o dobro de HOAc (Razão molar de 0,5 ) foi alimentado à coluna, elevada conversão e baixa pureza foram obtidas. A Tabela 4 exibe a fração molar dos componentes, obtida na corrente de produto de fundo para essa configuração.

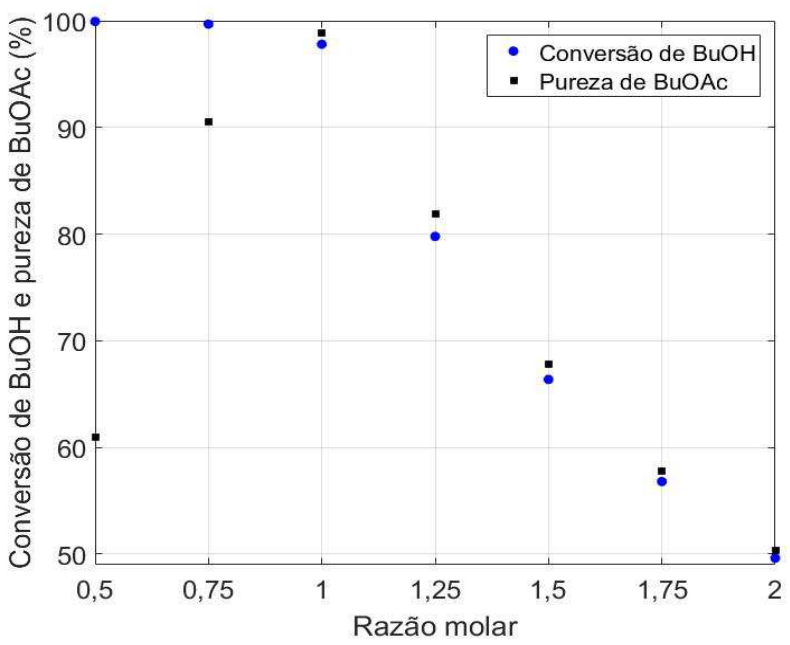

Figura 6 - Influência da razão molar dos reagentes no desempenho da DR.

Tabela 4 - Composição da corrente de produto de fundo para a razão molar BuOH/HOAc de 0,5 na alimentação.

$\begin{array}{cc}\text { Componente } & \text { Fração } \\ \mathrm{HOAc} & 0,3897 \\ \mathrm{BuOH} & 0,0003 \\ \mathrm{BuOAc} & 0,6100 \\ \mathrm{HOH} & 0,0000\end{array}$


Observa-se que a maior parte das impurezas foram originadas pela presença do HOAc. Esse resultado foi previsto com base nos dois últimos parágrafos da Subseção 3.2, em que o mesmo fenômeno aconteceu, porém menos intenso devido à menor quantidade de HOAc alimentada. O esgotamento do HOAc foi a separação mais importante nos estágios inferiores ao de sua alimentação fresca. Operar com excesso desse componente prejudicou o desempenho da DR.

A pureza foi melhorada à medida que a razão se tornou equimolar em ordem crescente, enquanto que a conversão se manteve. A melhor combinação de conversão e de pureza foi verificada na razão equimolar. Em razões superiores observa-se um mau desempenho, de modo que quantidade excessiva de $\mathrm{BuOH}$ foi distribuída ao longo da coluna. Assim, o número de estágios empregados não foi suficiente para consumi-lo e separa-lo adequadamente.

Verifica-se esse resultado por meio da Tabela 5. Diferente dos resultados da Figura 2 e da Tabela 4, o BuOH tornou-se a principal impureza nas correntes de produto de topo e de fundo. Além disso, segundo Gangadwala et al. (2003) e Singh et al. (2005), o excesso desse componente na seção reativa combinado à alta temperatura e à alta carga de catalisador, leva à síntese de dibutil éter, produto indesejável.

Tabela 5 - Composição das correntes de produto de topo e de fundo para a razão molar BuOH/HOAc de 2 na corrente de alimentação.

\begin{tabular}{|ccc|}
\hline Componente & \multicolumn{2}{c|}{ Fração molar } \\
& Produto de topo & Produto de fundo \\
HOAc & 0,0000 & 0,0038 \\
BuOH & 0,4619 & 0,4928 \\
BuOAc & 0,1934 & 0,5034 \\
HOH & 0,3447 & 0,0000 \\
\hline
\end{tabular}

\subsection{Influência do Número de Estágios Reativos (ER)}

A influência do número de ER na conversão de $\mathrm{BuOH}$ e na pureza de BuOAc está apresentada na Figura 7. Bom desempenho foi obtido a partir de três ER. Embora sejam poucos ER, a carga de líquido especificado por estágio foi suficiente para que a reação ocorresse em uma taxa satisfatória. A introdução de mais ER levou ao aumento da conversão e da pureza. Esse resultado foi consequência do maior tempo de residência dos reagentes na seção reativa. A inclusão de mais estágios reativos ocasionou um efeito análogo àquele de aumentar o número de reatores CSTR em série (Tian et al., 2012).

A conversão e a pureza evoluíram rapidamente e se estabilizaram a partir de 5 ER. Isso indica que para a vazão de alimentação configurada, o número de ER foi mais do que suficiente para alcançar o alto consumo dos reagentes. Assim, após um determinado valor de conversão ser alcançado, a seção reativa atuou principalmente como uma seção de esgotamento, contribuindo para a purificação do BuOAc.

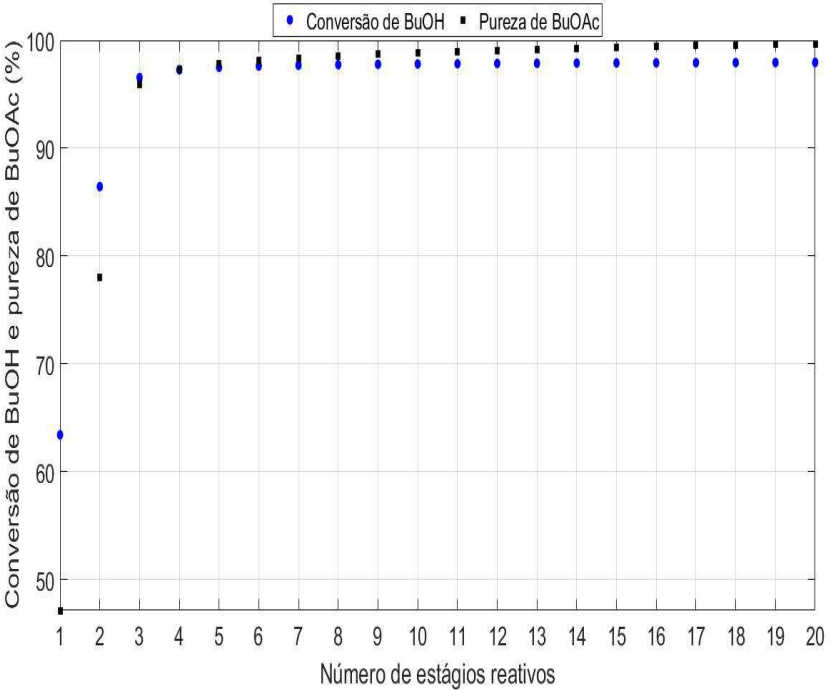

Figura 7 - Influência do número de estágios reativos no desempenho da DR.

\subsection{Influência do Número de Estágio não Reativos (ENR)}

A influência do número de ENR na conversão de $\mathrm{BuOH}$ e na pureza de BuOAc está apresentada na Figura 8. O refervedor foi considerado na contagem dos ENR. Além disso, quando a configuração correspondeu a um número par de ENR, priorizou-se acrescentar o ENR excedente na seção de esgotamento. Quando a coluna operou somente com a seção reativa, bom desempenho foi obtido, de modo que $\mathrm{BuOH}$ foi consumido satisfatoriamente e BuOAc foi purificado até um nível adequado.

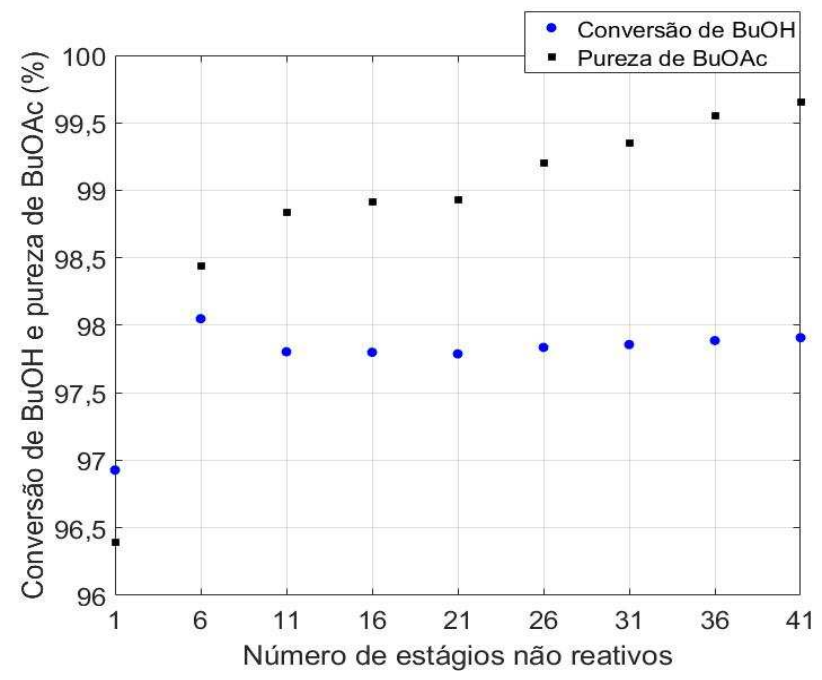

Figura 8 - Influência do número de estágios não reativos no desempenho da DR.

Leve melhora na conversão e melhora significativa na pureza foram obtidas, conforme ENR foram adicionados. A conversão foi levemente afetada devido à sua dependência ser mais forte com os parâmetros reativos do que com os não reativos. Por outro lado, a pureza é consideravelmente dependente dos parâmetros da seção de esgotamento, e teve seu desempenho aprimorado conforme mais estágios foram adicionados. 


\subsection{Influência da Localização da Corrente de Alimentação na Seção Reativa}

A Figura 9 apresenta a influência da localização da corrente de alimentação na seção reativa para a conversão de $\mathrm{BuOH}$ e a pureza de BuOAc. Quanto mais próxima do topo da seção reativa a alimentação estava localizada, melhores resultados foram obtidos. A alimentação localizada no fundo da seção reativa levou ao pior desempenho.

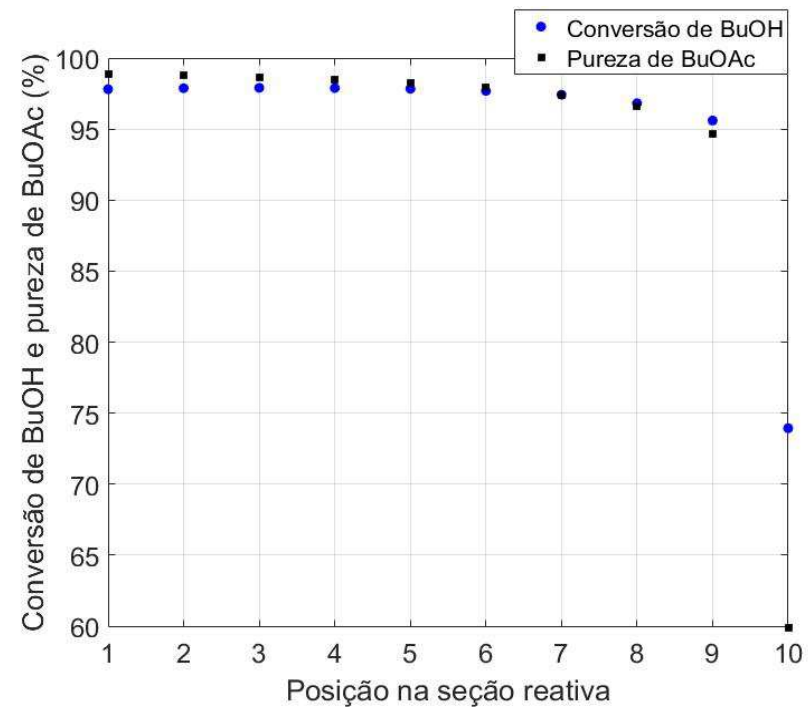

Figura 9 - Influência da localização da corrente de alimentada na seção reativa. Posição 1 e 10 denotam $06^{\circ}$ e $15^{\circ}$ estágios da coluna, respectivamente.

Para a alimentação configurada no fundo da seção reativa não foi obtida boa distribuição dos reagentes. Conforme apresentado nas Figuras 10 (a) e 10 (b), o BuOH esteve em frações elevadas ao longo da seção de retificação. O HOAc foi enriquecido no fluxo descendente. Como discutido na Seção 3.2, o HOAc tende a constituir a corrente de produto de fundo.

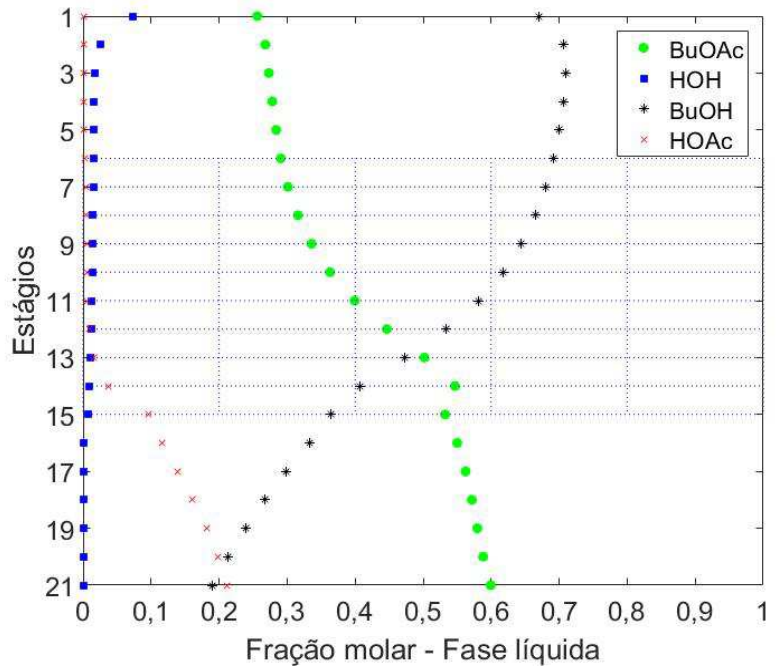

(a)

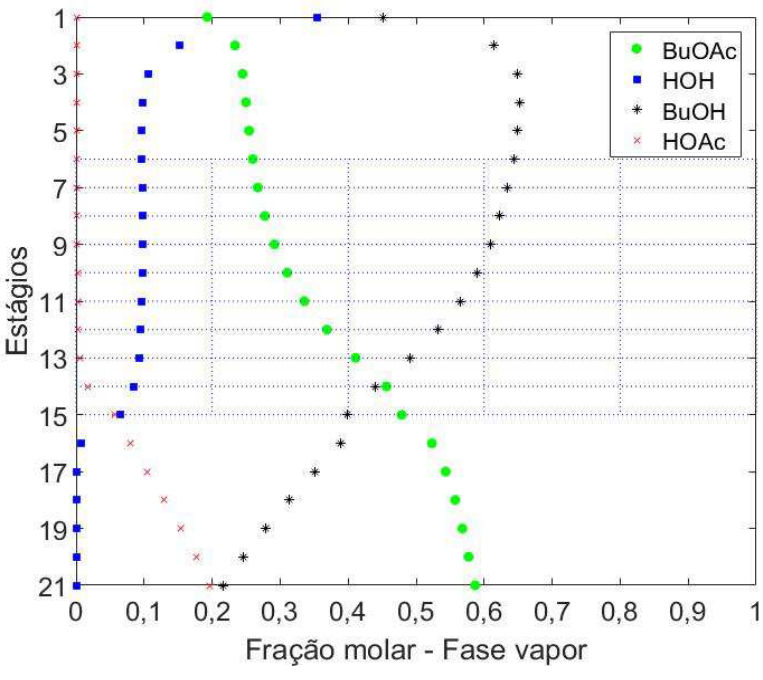

(b)

Figura 10 - Distribuição da fração molar dos componentes ao longo da coluna com a alimentação localizada no fundo da seção reativa: (a) fase líquida; (b) fase vapor. A região hachurada indica a seção reativa.

Essa tendência evitou a distribuição do HOAc na seção reativa e prejudicou a taxa da reação direta. A $\mathrm{HOH}-$ componente mais volátil do sistema - na forma de vapor, esteve em quantidades consideráveis ao longo da seção reativa, conforme apresentado na Figura 10 (b). Quando parte de sua fração condensou no escoamento contracorrente, ela encontrou o BuOAc na fase líquida. O contato entre esses componentes levou à reação reversa, conforme apresentado na Figura 11.

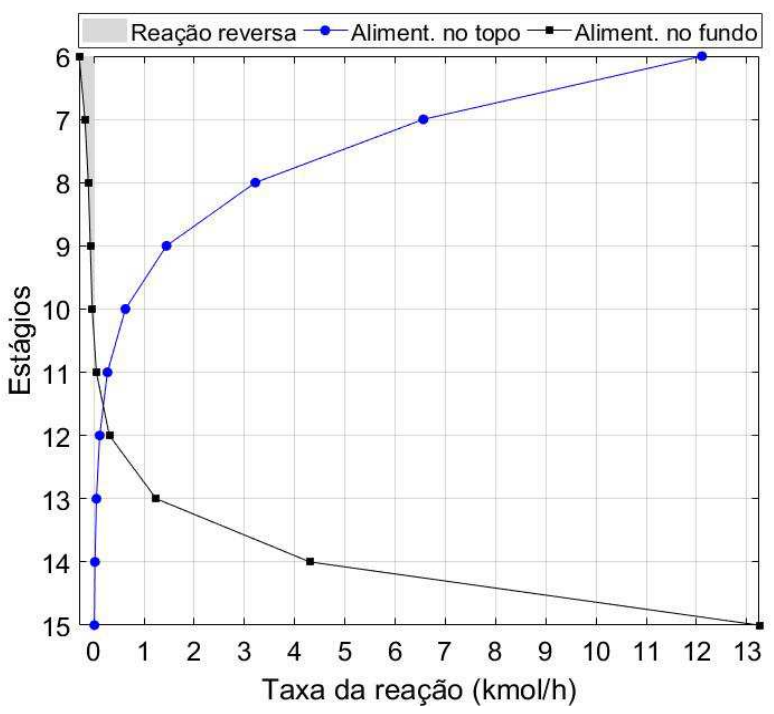

Figura 11 - Comparação entre os perfis de taxa da reação para a alimentação localizada no topo e no fundo da seção reativa, respectivamente. 
Além disso, o efeito azeotrópico da $\mathrm{HOH}$ com o $\mathrm{BuOH}$ e com o BuOAc foi sentido em maior extensão, devido à sua quantidade considerável ao longo de toda a seção reativa e de retificação, na fase vapor. Em síntese, conclui-se que para a alimentação localizada no fundo da seção reativa, os fenômenos descritos levaram à baixa produção de BuOAc e ao baixo consumo do BuOH. O enriquecimento do HOAc na seção de esgotamento reduziu drasticamente a pureza de BuOAc na corrente de fundo.

A alimentação no topo permitiu que a seção reativa consumisse grande parte do HOAc, que seria enriquecido no fluxo descendente. Permitiu também que os estágios inferiores esgotassem o HOAc remanescente, conferindo alta pureza de BuOAc na corrente de produto de fundo. O enriquecimento da $\mathrm{HOH}$ aconteceu na seção de retificação, evitando a reação reversa. $\mathrm{O} \mathrm{BuOH}$ foi bem distribuído ao longo da coluna, o que levou à sua alta conversão.

\subsection{Influência da Localização da Seção Reativa}

A localização da seção reativa foi avaliada em três regiões da coluna. Em cada uma foi estudada a taxa da reação, a conversão de $\mathrm{BuOH}$ e a pureza de $\mathrm{BuOAc}$. Os resultados estão apresentados na Figura 12. As Configurações 1, 2 e 3 referemse à seção reativa localizada no meio da coluna $\left(6^{\circ}\right.$ ao $15^{\circ}$ estágio), no topo da coluna ( $1^{\circ}$ ao $10^{\circ}$ estágio) e no fundo da coluna $\left(11^{\circ}\right.$ ao $20^{\circ}$ estágio), respectivamente. Para todas as configurações a alimentação foi realizada acima do $1^{\circ}$ estágio reativo.

Destaca-se que na Figura 12 os valores apresentados no eixo denominado "estágios reativos" não necessariamente representam a numeração real dos estágios da coluna, eles representam uma numeração particular da seção reativa. Assim a correspondência com os estágios da coluna é dada por:

- Configuração 1 (meio): $1^{\circ}$ ao $10^{\circ}$ estágios reativos $=6^{\circ}$ ao $15^{\circ}$ estágios da coluna.

- Configuração 2 (topo): $1^{\circ}$ ao $10^{\circ}$ estágios reativos $=1^{\circ}$ ao $10^{\circ}$ estágios da coluna.

- Configuração 3 (fundo): $1^{\circ}$ ao $10^{\circ}$ estágios reativos $=$ $11^{\circ}$ ao $20^{\circ}$ estágios da coluna.

Na Figura 12, observa-se que as maiores taxas da reação foram alcançadas para as Configurações 3 e 1, sobrepostas no gráfico. A taxa da reação é dependente da temperatura, conforme apresentado na Equações 3 e 4, quanto maior é a temperatura, maior é a taxa. O valor máximo de temperatura foi registrado no fundo da coluna, devido ao refervedor estar posicionado nesse local. Assim, as configurações localizadas nos estágios mais inferiores alcançaram as maiores taxas. A Configuração 2 produziu uma reação com taxa limitada a aproximadamente $7,45 \mathrm{kmol} / \mathrm{h}$, alcançada no segundo estágio reativo. Entre o primeiro e o segundo estágio reativo a Configuração 2 manteve a taxa da reação.

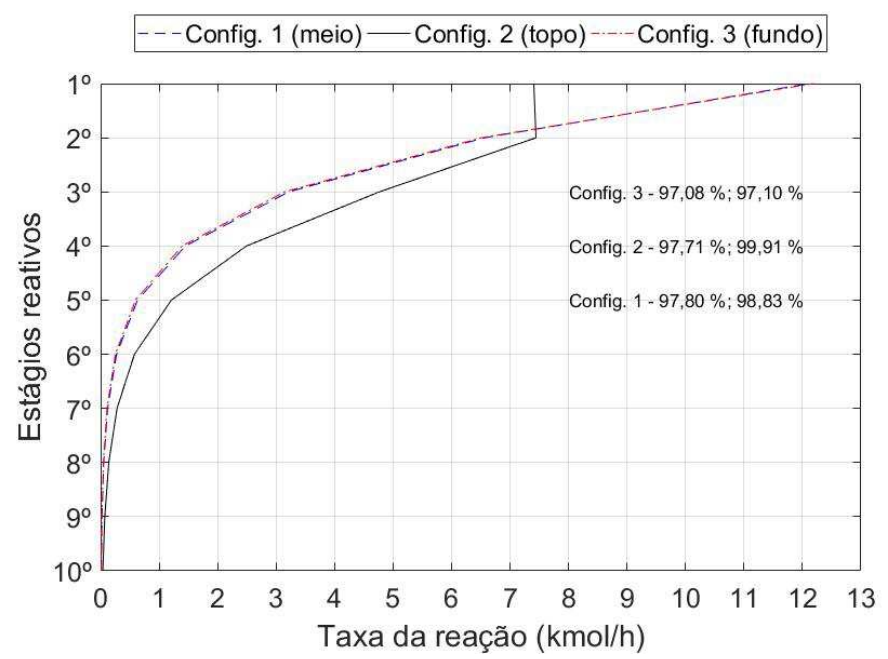

Figura 12 - Influência da posição da seção reativa no desempenho da DR. Os valores que acompanham as configurações representam a conversão de $\mathrm{BuOH}$ e a pureza de BuOAc, respectivamente.

Essas justificativas foram reforçadas por meio dos resultados da Figura 13. Ela apresenta a distribuição de temperatura nas seções reativas das configurações estudadas. $\mathrm{O}$ eixo denominado "estágios reativos" apresenta a mesma característica de contagem de estágios da Figura 12. A análise conjunta das Figuras 12 e 13 permite entender a razão pela qual a taxa da reação da Configuração 2 foi aproximadamente constante entre o primeiro e o segundo estágios reativos. A taxa da reação tende a reduzir à medida que se avança nos estágios reativos, devido aos reagentes estarem em uma concentração inferior ao estágio anterior, uma vez que foram consumidos. Em contrapartida, a temperatura aumenta à medida que se avança nos estágios reativos. No caso da Configuração 2, o aumento de temperatura do primeiro para o segundo estágio reativo foi suficiente para manter a taxa da reação. Esse aumento foi de aproximadamente $6,60{ }^{\circ} \mathrm{C}$, valor significativamente maior em relação aos observados na Configuração 1 e 3 , que foram de aproximadamente $2,40^{\circ} \mathrm{C}$ e $2,35^{\circ} \mathrm{C}$, respectivamente.

Em síntese, as Configurações 3 e 1 estiveram submetidas às maiores temperaturas, ao longo de maior parte da seção reativa. A Configuração 2 alcançou os menores valores de temperatura, portanto a taxa da reação nela não chegou à valores tão elevados quanto das demais configurações. 


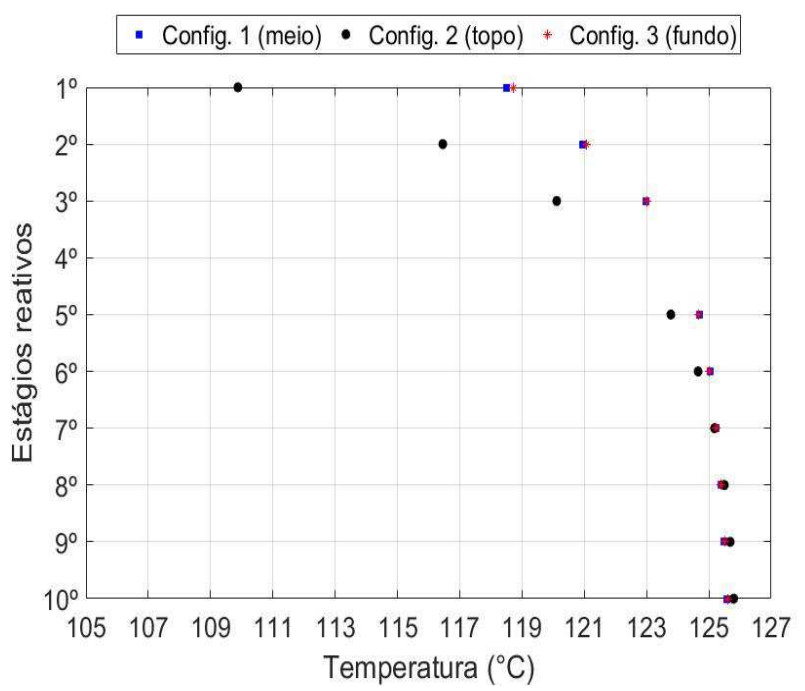

Figura 13 - Distribuição da temperatura ao longo da coluna para diferentes posições da seção reativa.

Em relação à conversão e à pureza, de acordo com a Figura 12 os valores alcançados foram similares. O maior valor de conversão foi obtido com a Configuração 1. A maior pureza foi produzida pela Configuração 2 e a pior pela Configuração 3 . Quanto mais próxima do topo da coluna a seção reativa estava localizada, mais estágios de separação estiveram disponíveis para a purificação do BuOAc, pois mais extensa foi a seção de esgotamento.

Dessa forma, a Configuração 2 se beneficiou de uma seção de esgotamento mais extensa. Em contrapartida, a Configuração 3 teve a seção reativa e a de esgotamento localizadas nos mesmos estágios. Assim, não houveram estágios para esgotar os demais componentes da corrente de produto de fundo até um nível elevado.

\subsection{Influência da Carga Térmica do Refervedor}

No fluxograma apresentado na Figura 1, não houve o emprego e a manipulação do parâmetro razão de refluxo. Isso decorreu da necessidade da separação de fases e do refluxo somente da fase orgânica. $O$ refluxo da fase orgânica não pode ser parametrizado diretamente. Ele depende da composição da corrente de produto de topo e da separação produzida no decantador (Sert e Atalay, 2011).

Segundo Sert e Atalay (2011), a única maneira de causar impacto significante na vazão da corrente de refluxo orgânico é por meio da variação carga térmica do refervedor. Assim, foi decidido estudar como a variação da carga térmica do refervedor influenciava no desempenho da DR.

A Figura 14 apresenta a influência da carga térmica do refervedor na conversão de $\mathrm{BuOH}$ e na pureza de BuOAc. Os dados estão em função da razão entre a vazão das correntes de produto de fundo (B) e de alimentação $(\mathrm{F})$, denominada por Razão B/F. A Tabela 6 apresenta a correspondência entre a razão $\mathrm{B} / \mathrm{F}$, a carga térmica do refervedor e a vazão da corrente de refluxo orgânico.

Na Tabela 6, a razão B/F se relacionou inversamente com a carga térmica do refervedor e com a vazão da corrente de refluxo orgânico. Essa dependência foi obtida pois o aumento da carga térmica do refervedor resultou no aumento do fluxo de vapor em elevada temperatura introduzido no processo e promoveu a maior vaporização da corrente de líquido, levando à maior vazão da corrente de produto de topo.

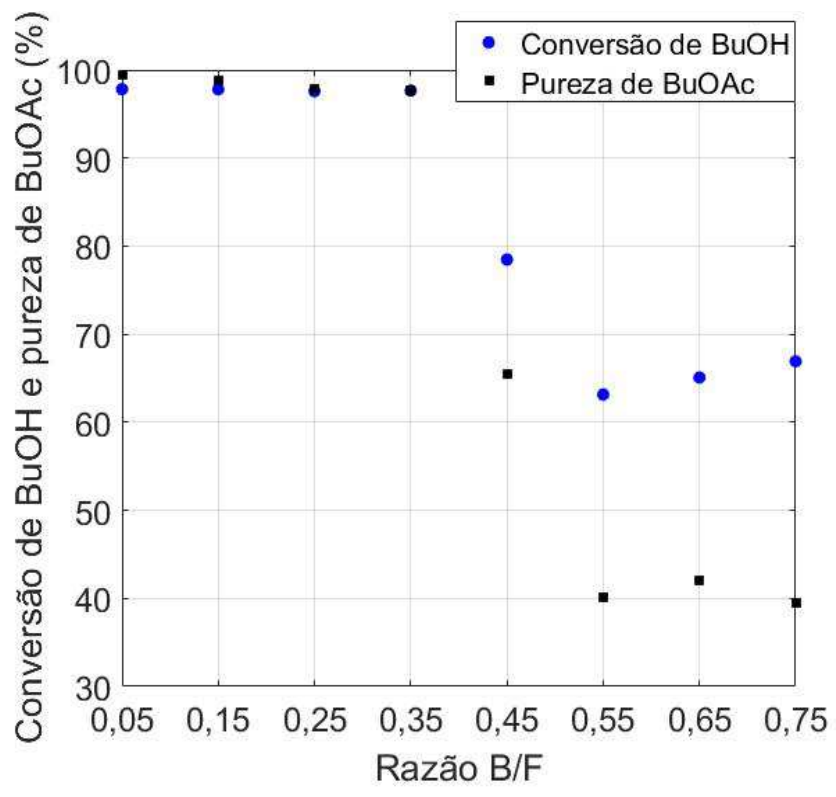

Figura 14 - Influência da carga térmica do refervedor no desempenho da DR. Os resultados estão em função da razão entre a vazão das correntes de produto de fundo (B) e de alimentação (F).

Tabela 6 - Correspondência da razão entre a vazão das correntes de produto de fundo (B) e de alimentação (F) com a carga térmica do refervedor e com a vazão da corrente de refluxo orgânico.

\begin{tabular}{ccc} 
Razão B/F & $\begin{array}{c}\text { Carga térmica } \\
\text { do refervedor } / \\
\mathbf{k W}\end{array}$ & $\begin{array}{c}\text { Vazão da } \\
\text { corrente de } \\
\text { refluxo } \\
\text { orgânico / kmol } \\
\mathbf{h}^{-1}\end{array}$ \\
\hline 0,0500 & 6525,4253 & 440,7630 \\
0,1500 & 1790,6631 & 114,7183 \\
0,2500 & 844,5983 & 49,6484 \\
0,3500 & 430,0196 & 21,3492 \\
0,4500 & 330,8944 & 16,4410 \\
0,5500 & 244,2004 & 12,8478 \\
0,6500 & 119,0165 & 9,5618 \\
0,7500 & 19,1692 & 6,5483
\end{tabular}

A maior vazão da corrente de produto de topo ocasionou o aumento da vazão da corrente de refluxo orgânico. Nesse sentido, em decorrência do aumento da vazão da corrente de produto de topo, menor vazão foi produzida na corrente de produto de fundo, o que conferiu menores razões $B / F$.

Da perspectiva da conversão e da pureza, menores razões $\mathrm{B} / \mathrm{F}$ permitiram que o líquido formador da corrente de produto de fundo fosse refluxado à coluna mais vezes e residisse mais tempo nos estágios, alcançando portanto maior purificação. Além disso, a maior temperatura promovida pela alta carga térmica, acelerou a taxa da reação nos estágios reativos, garantindo elevado consumo de $\mathrm{BuOH}$ e produção de $\mathrm{BuOAc}$. 
Operar em baixas razões B/F exige menos estágios para uma separação suficiente, porém requer maior carga térmica e confere menor produtividade de BuOAc. Contrariamente, em elevadas razões $\mathrm{B} / \mathrm{F}$ mais estágios são necessários, porém a carga térmica exigida é menor e a produtividade é maior. É importante que a coluna opere em uma condição capaz de produzir BuOAc em quantidade e pureza satisfatórias e apresente um custo operacional viável.

\subsection{Influência da Temperatura de Saída do Fluido de Processo no Condensador}

A Figura 15 apresenta a influência da temperatura de saída da corrento de produto de topo no condensador, na conversão de $\mathrm{BuOH}$ e na pureza de BuOAc. Observa-se que o aumento dessse parâmetro resultou no aumento da conversão e da pureza, embora a pureza em menor variação. Além disso, esse aumento levou à redução da vazão da corrente aquosa, originada pela decantação da corrente de produto de topo.

A Tabela 7 apresenta a relação entre a temperatura de saída da corrente de produto de topo no condensador e a vazão dos componentes na fase aquosa. Observa-se que o aumento da temperatura de saída do condensador foi acompanhado da redução da vazão de $\mathrm{HOAc}$, de $\mathrm{BuOH}$ e de BuOAc, além do aumento da vazão de $\mathrm{HOH}$. Observa-se também que a redução total na vazão de $\mathrm{BuOH}$ e o aumento total na vazão de $\mathrm{HOH}$ aconteceram em valores de aproximadamente $0,8 \mathrm{kmol} / \mathrm{h}$.

Em decorrência da proporcionalidade na redução da vazão de $\mathrm{BuOH}$ e no aumento da vazão de $\mathrm{HOH}$, conclui-se que a redução da vazão da corrente aquosa observada na Figura 15 foi dada principalmente pela perda dos componentes HOAc e BuOAc para a fase orgânica. Operar em altas temperaturas de saída do condensador levou à decantação a produzir fases aquosas com elevado conteúdo de $\mathrm{HOH}$.

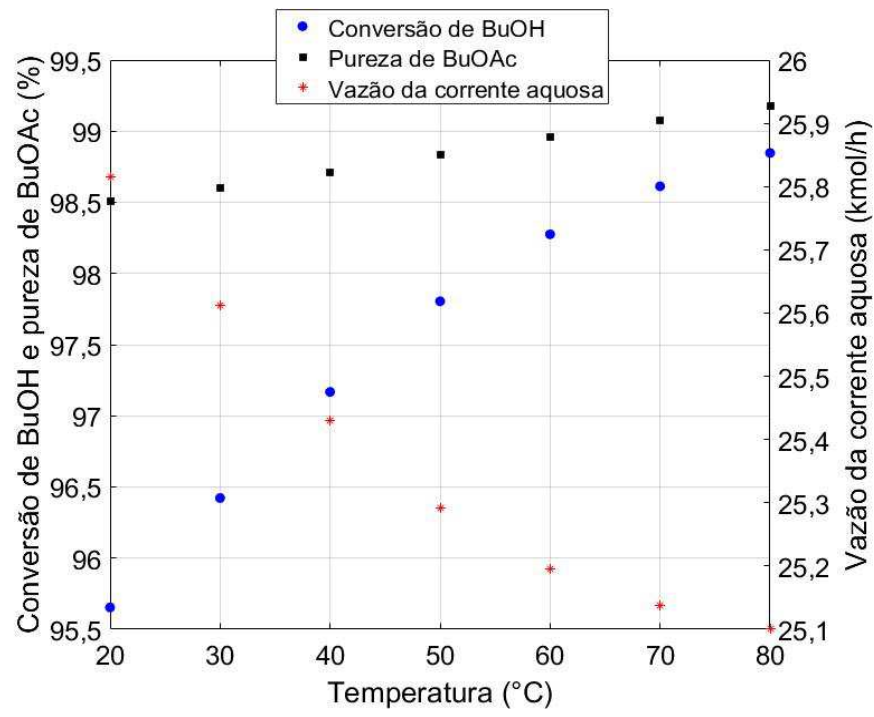

Figura 15 - Influência da temperatura do condensador no desempenho da DR.
Tabela 7 - Influência da temperatura do condensador na vazão dos componentes na corrente aquosa.

\begin{tabular}{ccccc}
$\begin{array}{c}\text { Temperatura } \\
\text { do } \\
\text { condensador / }\end{array}$ & HOAc & BuOH & BuOAc & HOH \\
${ }^{\circ}$ C & & & & \\
20 & 0,7281 & 1,0864 & 0,0888 & 23,9118 \\
30 & 0,5548 & 0,8941 & 0,0608 & 24,1028 \\
40 & 0,3899 & 0,7036 & 0,0420 & 24,2941 \\
50 & 0,2627 & 0,5485 & 0,0308 & 24,4000 \\
60 & 0,1754 & 0,4301 & 0,0241 & 24,5663 \\
70 & 0,1193 & 0,3462 & 0,0200 & 24,6514 \\
80 & 0,0865 & 0,2875 & 0,0180 & 24,7087 \\
\hline
\end{tabular}

Nesse sentido o $\mathrm{BuOH}$ constituiu principalmente a fase orgânica. $\mathrm{O}$ refluxo dessa fase permitiu maior conversão dele e conequentemente maior pureza de BuOAc. Embora melhor desempenho tenha sido obtido em altas temperaturas de saída do condensador, ressalta-se a importância de avaliar o custo da utilidade e a diferença de temperatura $(\Delta \mathrm{T})$ operante. Operar com altas temperaturas de saída, produz baixos $\Delta \mathrm{T}$, exigem maiores áreas e, portanto encarecem o projeto da coluna de DR.

\subsection{Projeto Otimizado}

Com base nos resultados obtidos foi proposto um projeto otimizado em termos de pureza de BuOAc na corrente de fundo. Os resultados globais estão apresentados na Figura 16. O projeto otimizado modificou o número de estágios da coluna para 15 , considerando o refervedor. Foram mantidos os 10 estágios reativos, porém reduziu-se o número de estágios não reativos para 4 , sendo 2 para a seção de retificação e 2 para a seção de esgotamento. Desse modo, a seção reativa ocupou a faixa do $3^{\circ}$ ao $12^{\circ}$ estágio. A alimentação foi realizada no topo da seção reativa, ou seja, acima do $3^{\circ}$ estágio. A razão $\mathrm{B} / \mathrm{F}$ foi de 0,2 , o que exigiu uma carga térmica de $1032,22 \mathrm{~kW}$ do refervedor . A temperatura de saída da corrente de produto de topo no condensador foi de $80{ }^{\circ} \mathrm{C}$, o que resultou na absorção de uma carga térmica de $1198,27 \mathrm{~kW}$. Os demais parâmetros foram mantidos. O projeto otimizado resultou em uma conversão de $\mathrm{BuOH}$ de 99,22 \% e pureza de BuOAc de 99,60\%.

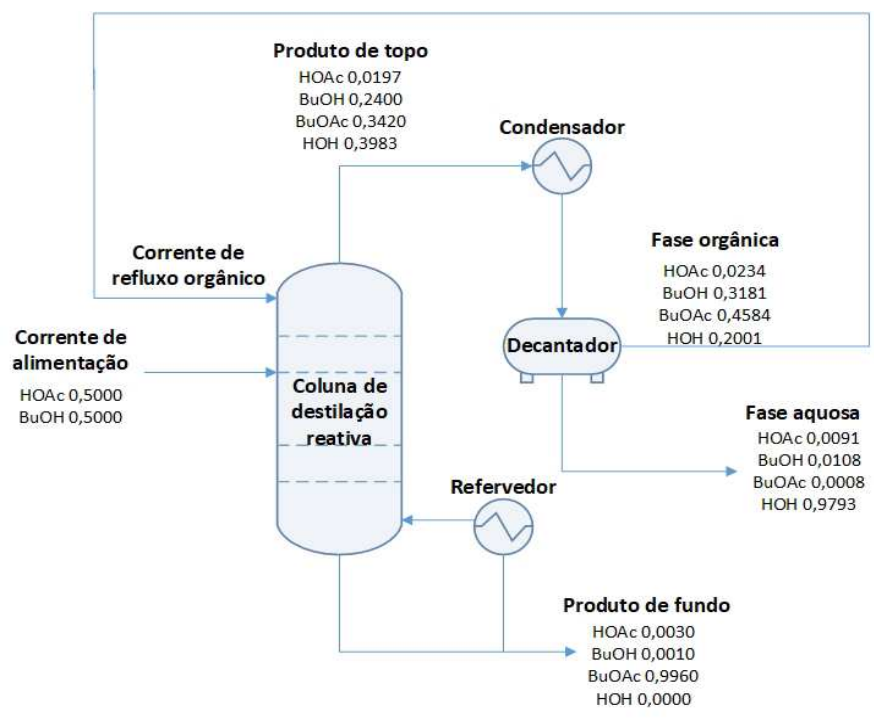

Figura 16 - Fração molar global obtida para as principais correntes do processo otimizado. 


\section{CONCLUSÃO}

Simulou-se o processo de produção de $\mathrm{BuOAc}$ via DR. O programa Aspen Plus, configurado com o módulo RadFrac e com o equilíbrio dos componentes modelado pelo método de propriedade UNIQUAC foi capaz de avaliar quantitativamente o desempenho da DR por meio da variação de diversos parâmetros operacionais. A configuração somente com uma coluna de DR foi considerada. Os resultados foram detalhadamente discutidos, de modo que o efeito da variação da posição da seção reativa na coluna e da temperatura de saída do fluido de processo no condensador foram complementados à literatura. Foi proposto um projeto otimizado em termos de pureza de BuOAc na corrente de fundo. Esse projeto resultou em uma conversão de $\mathrm{BuOH}$ de 99,22 \% e pureza de BuOAc de $99,60 \%$.

\section{A GR A D E C I M EN T O S}

Os autores agradecem à Coordenação de Aperfeiçoamento de Pessoal de Nível Superior (CAPES) por possibilitar a realização desse trabalho.

REFER E N C I A S

CARDONA, C. A.; MARULANDA, V. F.; YOUNG, D. Analysis of the environmental impact of butyl acetate process through the WAR algorithm. Chemical Engineering Science. V. 59, p. 5839-5845, setembro 2004.

CHO, M.; JO, S.; KIM, G.; HAN, M. Entrainer-Enhanced Reactive Distillation for the Production of Butyl Acetate. Industrial \& Engineering Chemistry Research. V. 53, p. 8095-8105, abril, 2014.

HANIKA J.; KOLENA, J.; SMEJKAL Q. Butyl acetate via reactive distillation - modelling and experiment. Chemical Engineering Society. V. 54, p. 5205-5209. 1999.

HIWALE, R.; MAHAJAN, Y. S.; BHATE, N. V.; MAHAJANI, S. M. Industrial Application of Reactive Distillation: Recent Trends. International Journal of Chemical Reactor Engineering. V. 2, 54 p. 2004.

GANGDWALA, J.; MANKAR, S.; MAHAJANI, S.; KIENLE A.; STEIN, E. Esterification of Acetic Acid with Butan-1-ol in the Presence of Ion-Exchange Resins as Catalyst. Industrial \& Engineering Chemistry Research. V. 42, 2146-2155, 2003.

LONING S.; HORST, C.; HOFFMANN, U. Theoretical Investigations on the Quaternary System $n$-Butan-1-ol, Butyl Acetate, Acetic Acid and Water. Chemical Engineering Technology. V. 23, n. 9, p. 789-794, 2000.

MALONE, M. F.; DOHERTY, M. F. Reactive Distillation. Industrial \& Engineering Chemistry Research. V. 39, n. 11, 3953-3957, 2000.

QIU, T.; HUANG, Z. X.; CHENG, C. B.; WU Y. X. Kinetics of Synthesis n-Butyl Acetate over Cation-Exchange Resin Catalyst. Chemical Reaction Engineering and Technology. V. 25, n. 4, p. 355-359, março 2009.

SAKUTH, M.; REUSCH, D.; JANOWSKY, R. Ullmann's Encyclopedia of Industrial Chemistry: Reactive Distillation. Wiley-VCH Verlag GmbH \& Co. KGaA, 2008, p. 263-276, v. 31.
SERT, E.; ATALAY, F. S. Esterification of Acetic Acid with Butan-1-ol: Operation in a Packed Bed Reactive Distillation Column. Chemical and Biochemical Engineering Quartely. V. 25, n. 2, p. 221-227, maio de 2011.

SINGH, A.; HIWALE, R.; MAHAJANI, S. M.; GUDI, R. D.; GANGADWALA J.; KIENLE, A. Production of Butyl Acetate by Catalytic Distillation. Theoretical and Experiments Studies. Industrial \& Engineering Chemistry Research. V. 44, p. 3042-3052. 2005.

STEINIGEWEG, S.; GMEHLING, J. n-Butyl Acetate Synthesis via Reactive Distillation: Thermodynamic Aspects, Reaction Kinetics, Pilot-Plant Experiments, and Simulation Studies. Industrial \& Engineering Chemistry Research. V. 41, 5483-5490. 2002.

STOYE, D. Ullmann's Encyclopedia of Industrial Chemistry: Solvents. Weinheim, Alemanha: Wiley-VCH Verlag GmbH \& Co. KGaA, 2000. p. 819-688, v. 33.

TIAN, H.; ZHAO, S.; ZHENG, H.; HUANG, Z. Reactive Distillation for Producing $n$-Butyl Acetate: Experiment and Simulation. Chinese Journal of Chemical Engineering. V. 20, n. 5, p. 980-987, dezembro. 2012. 